\title{
Molecular characterization and the effectiveness of native entomopathogenic Beauveria bassiana strains against adults of Mediterranean fruit fly (Ceratitis capitata)
}

\begin{abstract}
Abdessamad Imoulan ${ }^{1,2}{ }^{*}$, Saad Koraichi Ibnsouda ${ }^{3}$ and Abdellatif El Meziane ${ }^{2}$
${ }^{1}$ State Key Laboratory of Mycology, Institute of Microbiology, Chinese Academy of Sciences, Beijing 100101, China. ${ }^{2}$ Faculty of Science and Techniques, Cadi-Ayyad University Av. Abdelkarim EL Khattabi, 40000 Marrakesh, Morocco. ${ }^{3}$ Faculty of Sciences and Techniques, Sidi Mohamed Ben Abdellah University Fez 30000, Morocco.

${ }^{*}$ Corresponding Author. Email: imoulan@gmail.com

Copyright (C) 2016 Imoulan et al. This article remains permanently open access under the terms of the Creative Commons Attribution License 4.0, which permits unrestricted use, distribution, and reproduction in any medium, provided the original work is properly cited.

Received 5th February, 2016; Accepted 19th March, 2016

ABSTRACT: Molecular characterization of locally isolated Beauveria bassiana (Cordycipitaceae, Hypocreales) strains and their pathogenicity against Ceratitis capitata (Diptera: Tephritidae) adults are herein reported for the first time. Molecular identification based on the phylogenetic analyses of ITS-rDNA and combined data of TEF1 and Bloc, revealed that all fungal strains were conclusively assigned to $B$. bassiana clade. Interestingly, Maximum parsimony based-phylogeny analysis of the combined TEF1 and Bloc sequences detected additional genotypes among the subclades than ITS-rDNA analysis. Genetic diversity among strains was performed using random amplified polymorphic DNA (RAPD) markers. RAPD genotyping segregated all the strains into three clusters and characterized the 15 strains with different genotypes. RAPD-PCR clustering analysis showed that $B$. bassiana strains were relatively separated according to geographical origin. Molecular analyses using nuclear genes (TEF1 and Bloc) and RAPD markers suggest that $B$. bassiana is an aggregate of species, rather than a single species. Under laboratory conditions, $B$. bassiana strains were highly pathogenic to $C$. capitata adults with mortality rate in the range of $71.67-91.67 \%$. Based on the Average of Survival Time (AST) and median lethal times (LT50) values, fungal strains were able to reduce significantly lifespan of flies compared to controls. Further experiments under field conditions are required to evaluate the real contribution of these fungal strains as promising biological control agents against $C$. capitata adults in Morocco.
\end{abstract}

Keywords: Biocontrol, Bloc, ETF1, Morocco, phylogenetic analyses, RAPD-PCR.

\section{INTRODUCTION}

Mediterranean fruit fly (Medfly) Ceratitis capitata (Wiedermann) (Diptera: Tephritidae) is the most economically important species of fruit flies among Tephritidae throughout the world (White and ElsonHarris, 1994). In Morocco, Medfly takes from Argania spinosa forests the main refuge, from which continuously invades the surrounded agricultural crops, inducing heavy damages particularly to citrus orchards (Alaoui et al., 2010; Imoulan et al., 2011). As the fruit fly larvae feed and develop on the host pulp, fruit become rotten and inedible causing large direct economic losses (D'Aquino et al., 2011). So far, adult control measures have typically relied on the use of broad-spectrum chemical insecticides (Imoulan and El Meziane, 2013). However, the overuse of conventional insecticides has resulted in serious ecological imbalance (Arouri et al., 2015), raising the concern about the sustainability of the traditional approach for pest control.

As alternatives to chemical control, several microorganisms can serve as a promising approach to 
control fruit flies (Ekesi et al., 2007; Quesada-Moraga et al., 2006). Among these microbial agents, appears Beauveria bassiana (Cordycipitaceae, Hypocreales), an entomopathogenic fungus well-known by its potency to kill and to regulate insect population (Butt and Goettel, 2000). Unlike other microbial pathogens, entomopathogenic fungi have the advantage to infect and colonize their host through the host cuticle (Goettel et al., 2005). This property has prompted extensive researches in order to develop the efficient strains as biological control agents (Inglis et al., 2001). In Morocco, biological control approach remains at the embryonic scale with few works being published on the insect pathogenic fungi as biocontrol agents alongside to those established worldwide (Imoulan et al., 2011; Imoulan and El Meziane, 2013). These studies showed that some $B$. bassiana strains displayed high levels of pathogenicity against puparia and third instar larvae of Medfly, producing a large mortality rate ranging from 65 to $95 \%$ and caused significant reduction in the emergence of adult flies.

Beauveria is easily distinguished at genus level using morphological features, while species identification is complicated with the extensive overlap in morphological characteristics among species. Recently, all the species within this genus were well resolved using nuclear genes adapting the phylogenetic species recognition concept (Rehner et al., 2011). Genetic variability among strains have been performed using different molecular markers, providing more evidence on the diversity among strains than through morphological features solely. Molecular characterization using DNA-based methods such as RAPD-PCR analysis (Bidochka et al., 1994) can help, indeed, to distinguish individual strains in order to develop a specific marker for the environmental monitoring of the strains after being released in areas infested by $C$. capitata.

In Morocco, no detailed studies have been conducted on molecular characterization of Beauveria and their effectiveness against adult of $C$. capitata. In this study, we aimed to investigate the biological and molecular characterization of a subsample of Beauveria strains recovered from Moroccan forests of $A$. spinosa. The identification at species level was carried out using sequencing data from three nuclear genes and genetic diversity was assessed using RAPD-PCR genotyping. The antagonistic potential of the fungal strains was also evaluated under laboratory conditions against Medfly using adult stage. This investigation will help to raise the likelihood of a successful outcome in the biological control effort against Medfly in this country.

\section{MATERIALS AND METHODS}

\section{Fungal strains and growth conditions}

Beauveria strains were recovered from soil samples collected from $A$. spinosa forests in Morocco using Galleria mellonella baiting method (Imoulan et al., 2011). A total of 15 most pathogenic strains were selected from previous large screening for promising candidates using $C$. capitata pupae (Imoulan et al., 2011). To establish monosporic cultures, conidial suspensions of $1 \times 10^{5}$ conidia ml-1 were prepared and plated on PDA plates. The single colony propagated from single conidia was transferred into a new PDA dish and incubated at $25^{\circ} \mathrm{C}$.

\section{Genomic DNA extraction, PCR and sequencing}

Strains of Beauveria recovered from single conidia were grown as mycelia for 2 weeks in 250-ml flasks containing $100 \mathrm{ml}$ of potato dextrose broth. Cultures were then shaken at $150 \mathrm{rpm}$ on a rotary shaker at $25^{\circ} \mathrm{C}$ for 7 days in darkness. The mycelial samples were pelleted from liquid cultures by centrifugation for $10 \mathrm{~min}$ at $3500 \mathrm{rpm}$ (Eppendorf AG, Hamburg, Germany), subsequently washed twice with sterile double distilled water, and then lyophilized and stored at $-80^{\circ} \mathrm{C}$.

About $100 \mathrm{mg}$ of lyophilized mycelia for each strain was grounded in a sterile mortar using a pestle. Total genomic DNA was extracted following the modified CTAB method described by Yao et al. (1999). The mixtures were incubated for 2 hours at $65{ }^{\circ} \mathrm{C}$, then extracted twice with $24: 1$ chloroform : isoamyl alcohol, and centrifuged at $10,000 \mathrm{rpm}$ at $4{ }^{\circ} \mathrm{C}$ for $15 \mathrm{~min}$. The supernatant was transferred to a clean tube and mixed with $1 / 10$ volume of sodium acetate ( $3 \mathrm{M}, \mathrm{pH} 5.2)$. Total genomic DNA was precipitated by adding $2 / 3(\mathrm{v} / \mathrm{v})$ of cold isopropanol and chilled overnight at $-20^{\circ} \mathrm{C}$. DNA was recovered by centrifugation at $10,000 \mathrm{rpm}, 4^{\circ} \mathrm{C}$ for 10 min and washed twice with $70 \%$ alcohol, dried at room temperature and resuspended in TE buffer (10 Mm Tris$\mathrm{HCl}, \mathrm{pH}$ 8.0; $1 \mathrm{mM}$ EDTA, $\mathrm{pH}$ 8.0). The extracted DNA was stored at $-20^{\circ} \mathrm{C}$ until use.

Genomic DNA was used as template for PCR amplification of ITS regions (White et al., 1990), Elongation Factor 1-alpha (TEF1) (Rehner et al., 2005) and the Bloc nuclear intergenic (Rehner et al., 2006) using the following primer pairs ITS5 (5'GGAAGTAAAAGTCGTAACAAGG-3')/ITS4 TCCTCCGCTTATTGATATGC-3'), 983F (5'GCYCCYGGHCAYCGTGAYTTYAT-3')/ 2218R (5'ATGACACC RACRGCRACRGTYTG-3') and B5.1F (5'CGACCCGGCCAACTACTTTGA-3')/ B3.1R (5'GTCTTCCAGTACCACTACGCC-3'), respectively. The $P C R$ reactions were performed in a final volume of $50 \mu \mathrm{l}$ containing $25 \mu \mathrm{l} 2 \times$ Taq PCR Master Mix (Tiangen Biotech Co., LTD, China), $0.5 \mu$ of each primer $(10 \mu \mathrm{M})$, $10 \mathrm{ng}$ of genomic DNA and $23 \mu \mathrm{l}$ of RNase-Free water, and run in a thermocycler (Veritiß, Applied Biosystems, USA). Cycling conditions for amplification of ITS regions 
consisted of $5 \mathrm{~min}$ at $94^{\circ} \mathrm{C}$, followed by 35 cycles of 30 $\mathrm{s}$ at $94{ }^{\circ} \mathrm{C}, 30 \mathrm{~s}$ at $53{ }^{\circ} \mathrm{C}, 1 \mathrm{~min}$ at $72{ }^{\circ} \mathrm{C}$ and final extension step of $10 \mathrm{~min}$ at $72{ }^{\circ} \mathrm{C}$. Concerning the amplification of TEF1 gene, cycling conditions was performed using a touchdown procedure with $2 \mathrm{~min}$ initial denaturation at $94^{\circ} \mathrm{C}$ followed by 10 cycles of $30 \mathrm{~s}$ at 94 ${ }^{\circ} \mathrm{C}, 30 \mathrm{~s}$ at $66^{\circ} \mathrm{C}$ which was subsequently incrementally reduced by $1{ }^{\circ} \mathrm{C}$ per cycle, and $1 \mathrm{~min}$ at $72^{\circ} \mathrm{C}$. An additional 36 amplification cycles were then performed with the same conditions, however, with a fixed annealing temperature of $56^{\circ} \mathrm{C}$ and a final extension of $10 \mathrm{~min}$ at $72^{\circ} \mathrm{C}$. The cycling conditions of Bloc consisted of $3 \mathrm{~min}$ initial denaturation at $94^{\circ} \mathrm{C}$ for $3 \mathrm{~min}$ followed by 35 cycles of $30 \mathrm{~s}$ at $94^{\circ} \mathrm{C}, 30 \mathrm{~s}$ at $56^{\circ} \mathrm{C}, 1 \mathrm{~min}$ at $72^{\circ} \mathrm{C}$ and a final extension of $10 \mathrm{~min}$ at $72{ }^{\circ} \mathrm{C}$. PCR products were checked by electrophoresis on an agarose gel (1\%) at $100 \mathrm{~V}$ in $0.5 \times$ TAE buffer $(40 \mathrm{mM}$ Tris-Acetic acid, $\mathrm{pH}$ 8.0, $1 \mathrm{mM}$ EDTA), and sequenced with corresponding primers described above. The sequencing was performed by Beijing Genomics Institute (Beijing, China) by using a capillary sequencer (Applied Biosystems 3730 Analyzer, Foster City, California). All the sequences used in this study were submitted to GenBank with accession numbers given in Table 1.

\section{Phylogenetic and data analyses}

All DNA sequences were assembled and edited manually as necessary using BioEdit ver. 7.2.5 (Hall, 1999). A total of 29 representative sequences of recognized species of Beauveria and one sequence of Cordyceps militaris (ARSEF 5050), the out group, were retrieved from GenBank (Table 1) and included in this study. Multiple sequence alignments were made using the Clustal W program (Thompson et al., 1997). Data sets of TEF1 and Bloc were concatenated into a single file using SequenceMatrix (Vaidya et al., 2011) and analyzed with Maximum parsimony (MP). ITS sequences were excluded from the phylogenetic analysis given of its limited information within ingroups (Rehner et al., 2011).

MP analysis was computed with PAUP* (Swofford, 2003) using 1000 replicates of heuristic search option of random sequence additions with branch swapping algorithm by tree bisection reconnection (TBR) under equal character weighting and MulTrees on. Branches of zero length were collapsed, and all parsimonious trees were saved. Alignment gaps were treated as missing data. Branch support was estimated by bootstrap analysis with 1,000 replicates (Felsenstein, 1985) executing the same search strategy as described above.

\section{Molecular characterization}

The RAPD-PCR reactions were carried out in a total volume of $25 \mu \mathrm{L}$ containing $2.5 \mu \mathrm{l}$ of Taq polymerase buffer $(10 \times), 0.2 \mathrm{mM}$ dNTP, $0.01 \mathrm{mM}$ primer, $2 \mathrm{mM}$ $\mathrm{MgCl}_{2}, 1 \cup$ Taq DNA polymerase (Promega) and $10 \mathrm{ng}$ of DNA. The thermocycler program included an initial denaturation at $94^{\circ} \mathrm{C}$ for 2 min followed by 40 cycles of denaturation at $94^{\circ} \mathrm{C}$ for $1 \mathrm{~min}$, annealing at $35^{\circ} \mathrm{C}$ for 1 min, and extension at $72{ }^{\circ} \mathrm{C}$ for $2 \mathrm{~min}$, and a final extension at $72{ }^{\circ} \mathrm{C}$ for $10 \mathrm{~min}$. RAPD products were separated by electrophoresis on $1.2 \%$ agarose gels. The molecular sizes of the amplified DNA bands were estimated using $1 \mathrm{~kb}$ ladder (Promega). Initially, 21 RAPD primers (OPC and OPT kits from Operon) were screened, out of which, only five most polymorph reproducible RAPD primers with easily recordable bands were selected for genetic diversity analysis.

To score RAPD markers, only clear and well resolved bands were analyzed as RAPD loci. Data from the RAPD banding patterns were coded in a binary data matrix of presence (1) or absence (0). Genetic similarity among the genotypes was estimated using Dice index of similarity, and the dendrogram was constructed using the UPMGA clustering method (Sneath and Sokal, 1973). All computations were performed using the NTSYSpc 2.1 package (Numerical Taxonomy System, Applied Biostatistics, Setauket, New York) (Rohlf, 2000).

\section{Pathogenicity against Medfly adults}

\section{Insects}

Field-infested fruits with Medfly larvae were collected from $A$. spinosa forests and kept in polyethylene containers with sterilized sand at $25 \pm 2{ }^{\circ} \mathrm{C}$ and a relative humidity of $65 \%$. Third instar larvae and pupae were collected daily by sifting the sand. Upon emergence, the flies were translocated in cages sized $40 \times 40 \times 40 \mathrm{~cm}$ and provided with mixture of sugar and yeast (3:1) and water. Insects were kept under laboratory conditions for several generations and the tenth one was used for the following pathogenicity tests.

\section{Inoculum, viability and bioassays}

Conidia were harvested by scraping the surface of 3week-old cultures and suspended in $10 \mathrm{ml}$ of sterile aqueous solution of $0.01 \%$ Tween 80 . Conidial concentrations were determined using a haemocytometer following serial dilution in sterile distilled water. A standard initial concentration of $1 \times 10^{8}$ conidia ml-1 was made for each strain. The viability of conidia was determined by spread-plating $0.1 \mathrm{ml}$ of conidial suspension titrated to $3 \times 10^{6}$ conidia ml-1 on PDA plates. Sterile microscope cover slips were placed on each plate and incubated at $25{ }^{\circ} \mathrm{C}$. Percentage germination was scored after $20 \mathrm{~h}$ at $200 \times$ magnification by counting 100 conidia randomly for each replicate. Conidia were 
Table 1 Strains used in Beauveria phylogenetic analysis, their origin, substrate and GenBank numbers

\begin{tabular}{|c|c|c|c|c|c|c|}
\hline \multirow{2}{*}{ Strain } & \multirow{2}{*}{ Species } & \multirow{2}{*}{ Locality } & \multirow{2}{*}{ Host/Substrate } & \multicolumn{3}{|c|}{ GenBank number } \\
\hline & & & & ITS & Bloc & TEF \\
\hline OUJ4.111 & B. bassiana & Morocco, North & Soil & KT378221 & KU663905 & KT748529 \\
\hline OUJ6.124 & B. bassiana & Morocco, North & Soil & KT378222 & KU663906 & KT748530 \\
\hline OUJ18.118 & B. bassiana & Morocco, North & Soil & КT378226 & KU663907 & KT748531 \\
\hline OUJ18.120 & B. bassiana & Morocco, North & Soil & KT378227 & KU663908 & KT748532 \\
\hline OUJ18.122 & B. bassiana & Morocco, North & Soil & KT378228 & KU663909 & KT748533 \\
\hline OUJ5.32 & B. bassiana & Morocco, North & Soil & KT378230 & KU663910 & KT748534 \\
\hline OUJ20.75 & B. bassiana & Morocco, North & Soil & КT378231 & KU663911 & KT748535 \\
\hline OUJ14.96 & B. bassiana & Morocco, North & Soil & КT378225 & KU663912 & KT748536 \\
\hline ESR1.1 & B. bassiana & Morocco, West & Soil & КT378218 & KU663913 & KT748537 \\
\hline ESR4.16 & B. bassiana & Morocco, West & Soil & KT378219 & KU663914 & KT748538 \\
\hline SMI2.31 & B. bassiana & Morocco, West & Soil & KT378220 & KU663915 & KT748539 \\
\hline TAM6.2 & B. bassiana & Morocco, West & Soil & KT378229 & KU663916 & KT748540 \\
\hline AML1.289 & B. bassiana & Morocco, South & Soil & KT378223 & KU663917 & KT748541 \\
\hline AMS8.366 & B. bassiana & Morocco, South & Soil & KT378224 & KU663918 & KT748542 \\
\hline BAH4.94 & B. bassiana & Morocco, South & Soil & КT378232 & KU663919 & KT748543 \\
\hline ARSEF 300 & B. bassiana & Australia & Hemiptera: Lygaeidae & AY532015 & HQ880690 & AY531924 \\
\hline ARSEF 751 & B. bassiana & Vietnam & Coleoptera: Chrysomelidae & AY532045 & HQ880694 & AY531954 \\
\hline ARSEF 1040 & B. bassiana & Japan & Lepidoptera: Bombycidae & AY531972 & HQ880689 & AY531881 \\
\hline ARSEF 4622 & B. australis & Australia & Orthoptera: Acridiidae & HQ880788 & HQ880721 & HQ880996 \\
\hline ARSEF 4598 & B. australis & Australia & Soil & HQ880789 & HQ880720 & HQ880995 \\
\hline ARSEF 617 & B. brongniartii & France & Coleoptera: Scarabaeidae & HQ880782 & HQ880713 & HQ880991 \\
\hline ARSEF 10278 & B. brongniartii & USA, Oregon & Soil: Rhizosphere & HQ880769 & HQ880700 & HQ880979 \\
\hline ARSEF 10280 & B. brongniartii & USA, Oregon & Soil: Rhizosphere & HQ880771 & HQ880702 & HQ880981 \\
\hline ARSEF 4474 & B. asiatica & China & Coleoptera: Scarabaeidae & AY531936 & HQ880717 & AY531936 \\
\hline ARSEF 4850 & B. asiatica & Republic of Korea & Coleoptera: Cerambycidae & AY531936 & HQ880718 & AY531937 \\
\hline ARSEF 7279 & B. sungii & Republic of Korea & Coleoptera: Scarabaeidae & HQ880813 & HQ880744 & HQ881009 \\
\hline ARSEF 7280 & B. sungii & Republic of Korea & Coleoptera: Scarabaeidae & HQ880814 & HQ880745 & HQ881010 \\
\hline ARSEF 7281 & B. sungii & Republic of Korea & Coleoptera: Scarabaeidae & HQ880815 & HQ880746 & HQ881011 \\
\hline ARSEF 7760 & B. malawiensis & Malawi & Coleoptera: Cerambycidae & DQ376247 & HQ880756 & DQ376246 \\
\hline ARSEF 4755 & B. malawiensis & Australia & Soil & HQ880825 & HQ880754 & HQ881015 \\
\hline ARSEF 7117 & B. caledonica & USA, Georgia & Orthoptera: Gryllacrididae & HQ880820 & HQ880751 & HQ881013 \\
\hline ARSEF 8024 & B. caledonica & Denmark & Coleoptera: Scarabaeidae & HQ880818 & HQ880749 & HQ881012 \\
\hline
\end{tabular}

${ }^{*}$ GenBank accession numbers in bold are sequences generated in this study.

NA: not available. 
Table 1. Contd.

\begin{tabular}{lllllll}
\hline ARSEF 4149 & B. amorpha & Australia & Coleoptera: Scarabaeidae & HQ880804 & HQ880735 & HQ881006 \\
ARSEF 7542 & B. amorpha & USA, Colorado & Hymenoptera: Formicidae & HQ880805 & HQ880736 & HQ881007 \\
ARSEF 1855 & B. pseudobassiana & Canada & Coleoptera: Scolytidae & HQ880796 & HQ880727 & HQ880999 \\
ARSEF 2997 & B. pseudobassiana & Canada & Hymenoptera: Vesidae & HQ880797 & HQ880728 & HQ881000 \\
ARSEF 3216 & B. pseudobassiana & USA, Wisconsin & Thysanoptera: Thripidae & AY532019 & HQ880725 & AY531927 \\
ARSEF 2694 & B. varroae & Switzerland & Coleoptera: Curculionidae & HQ880802 & HQ880733 & HQ881004 \\
ARSEF 8257 & B. varroae & France & Acari: Varroidae & HQ880800 & HQ880731 & HQ881002 \\
ARSEF 8259 & B. varroae & France & Acari: Varroidae & HQ880801 & HQ880732 & HQ881003 \\
RCEF 3903 & B. sinensis & China, Anhui & Lepidoptera: Geometridae & HM135176 & NA & HQ270151 \\
RCEF 5500 & B. lii & China,Shaanxi & Coleoptera: Coccinellidae & JN689372 & JN689373 & JN689371 \\
ARSEF 7032 & B. kipukae & USA, Hawaii & Homoptera: Delphacidae & HQ880803 & HQ880734 & HQ881005 \\
AESEF 2922 & B. vermiconia & Chile & Soil & AY532012 & HQ880753 & AY531920 \\
ARSEF 5050 & Cordyceps militaris & USA, New York & Lepidoptera & HQ880829 & NA & HQ881020 \\
\hline
\end{tabular}

considered to have germinated when the germ tube was longer than the conidia diameter.

Laboratory bioassays were undertaken in controlled environment room at $25 \pm 2{ }^{\circ} \mathrm{C}, 65 \% \mathrm{RH}$ and 12:12 (L:D) photoperiod. Newly molted adults $(20-24 \mathrm{~h})$ that had previously been cold anesthetized were treated with $2 \mu \mathrm{l}$ of the conidial suspension of $10^{8}$ conidia $\mathrm{ml}^{-1}$ on ventral surface of the abdomen. Controls were treated with the same volume of a sterile aqueous solution of $0.01 \%$ Tween 80 . The treated flies were then released into cages $(40 \times 40 \times 40 \mathrm{~cm})$ and provided with water and mixture of sugar and yeast (3:1). Each treatment was replicated three times with 40 insects per replicate and all the bioassays were tested at the same time. Mortality was recorded daily and dead flies were removed to prevent horizontal transmission of conidia. Dead insects were immediately surface sterilized with $1 \%$ sodium hypochlorite for $1 \mathrm{~min}$, followed by three rinses with sterile distilled water. The cadavers were subsequently transferred to Petri dishes lined with damp sterilized filter paper and kept at $25^{\circ} \mathrm{C}$ to be inspected for fungal external growth. Mortality due to fungal infection was confirmed by microscopic examination.

\section{Statistical analysis}

Mortality data were normalized through Arcsine transformation and then examined using one-way analysis of variance (ANOVA) followed by mean separation by the Student-Newman-Keuls (SNK) test $(P=0.05)$. Time to kill $50 \%$ of the insects $\left(\mathrm{LT}_{50}\right)$ values was estimated using the probit analysis method for correlated dada (Throne et al., 1995). The average of survival time (AST) of adults was performed using the Kaplan-Meier survival analysis.

\section{RESULTS}

\section{Molecular identification and phylogenetic analysis}

PCR amplification of rDNA-ITS region consistently gave a single strong product of about $560 \mathrm{bp}$ in all examined Beauveria strains. Sequencing of the PCR amplicons, followed by Blast analysis, indicated that ITS sequences had 99 to $100 \%$ homology to those named B. bassiana in GenBank. MP analysis of ITS sequences including 29 representative sequences of recognized species of Beauveria clustered all Moroccan strains into $B$. bassiana clade, farther subdivided to three major sub-clades (data not shown).

PCR amplicons generated by sequencing for TEF1 and Bloc yielded a molecular size of approximately 1100 and 1500 bp for all the strains, respectively. The combined alignment of TEF1 and Bloc included a total of 2553 characters alignment comprising a total of 45 sequences, including 15 local Beauveria strains and 29 recognized Beauveria strains as well as Cordyceps militaris (ARSEF 5050) as outgroup. After the ambiguously aligned positions excluded, the final alignment comprised a total of 2553 characters (TEF1: 992; Bloc: 1561), of which 1800 were constant, 209 parsimony-uninformative and 544 parsimony- 


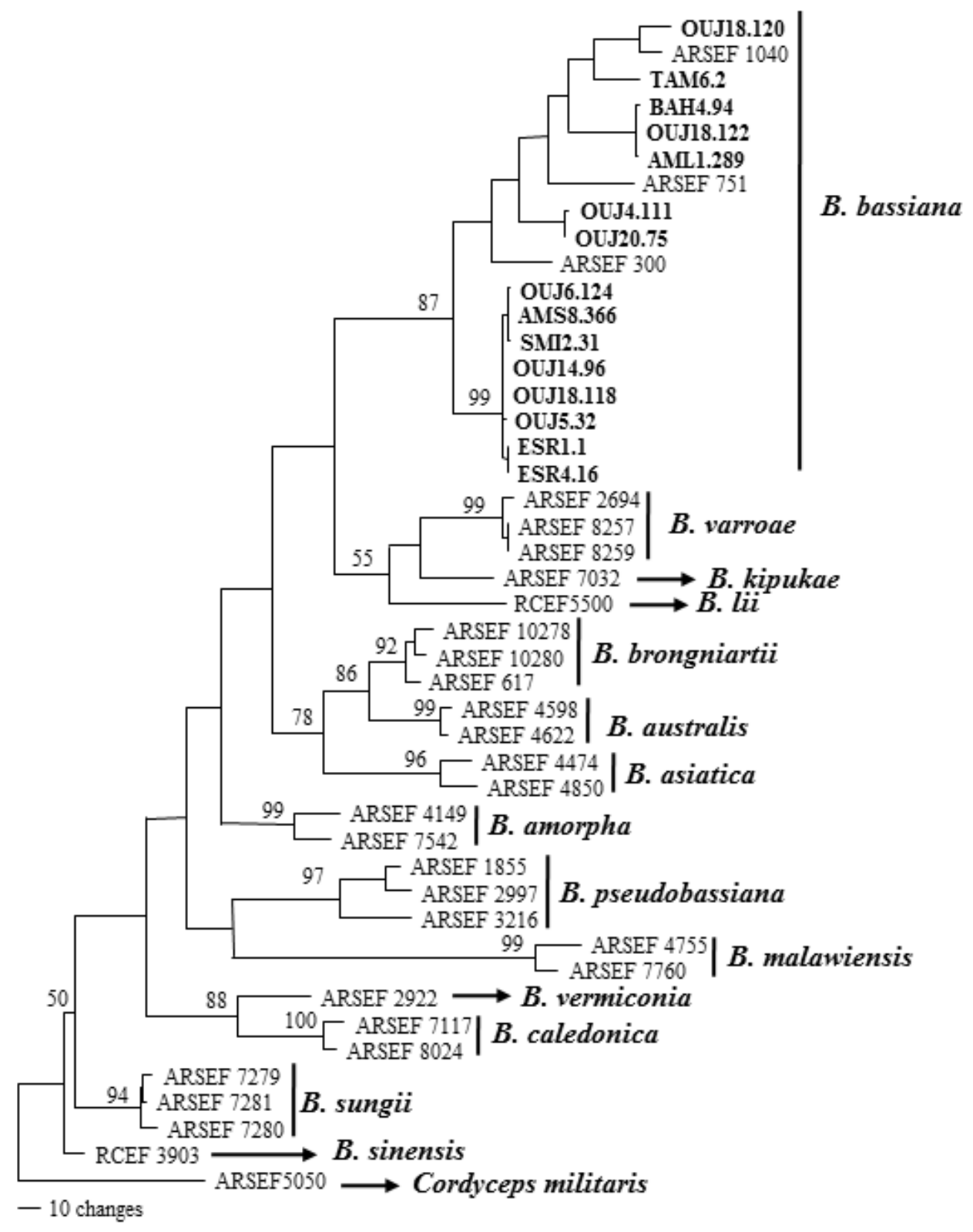

Figure 1. Phylogenetic tree of Beauveria based on Maximum parsimony of combined data of TFE1 and Bloc sequences. Bootstrap values $(\geq 50 \%)$ are labeled above branches. Terminal clades are labeled according to ARSEF accession numbers of individual isolates reported in Rehner et al. (2011), except RCEF5500 and RCEF3903 (Zang et al., 2012; Chan et al., 2013). Moroccan B. bassiana strains are in bold.

informative characters. The heuristic search yielded 61 most-parsimonious trees with tree length $(\mathrm{L})$ 1462, consistency index $(\mathrm{Cl}) \quad 0.617$, homoplasy index $\mathrm{HI}$ (0.383) and retention index (RI) 0.828.

MP phylogenetic analysis of the combined sequence dataset consistently resolved all Beauveria lineages in separated terminal branches with high bootstrap support values (Figure 1). This phylogenetic analysis clustered the 15 Moroccan Beauveria strains into $B$. bassiana clade with a bootstrap support of $87 \%$, which additionally partitioned on four distinct subclades (Figure 1). This result was consistent with the MP phylogenetic relationship based on ITS sequences (data not shown). However, phylogenetic analysis based combined data was more reliable in detecting additional genotypes within $B$. bassiana sub-clades (Figure 1). 


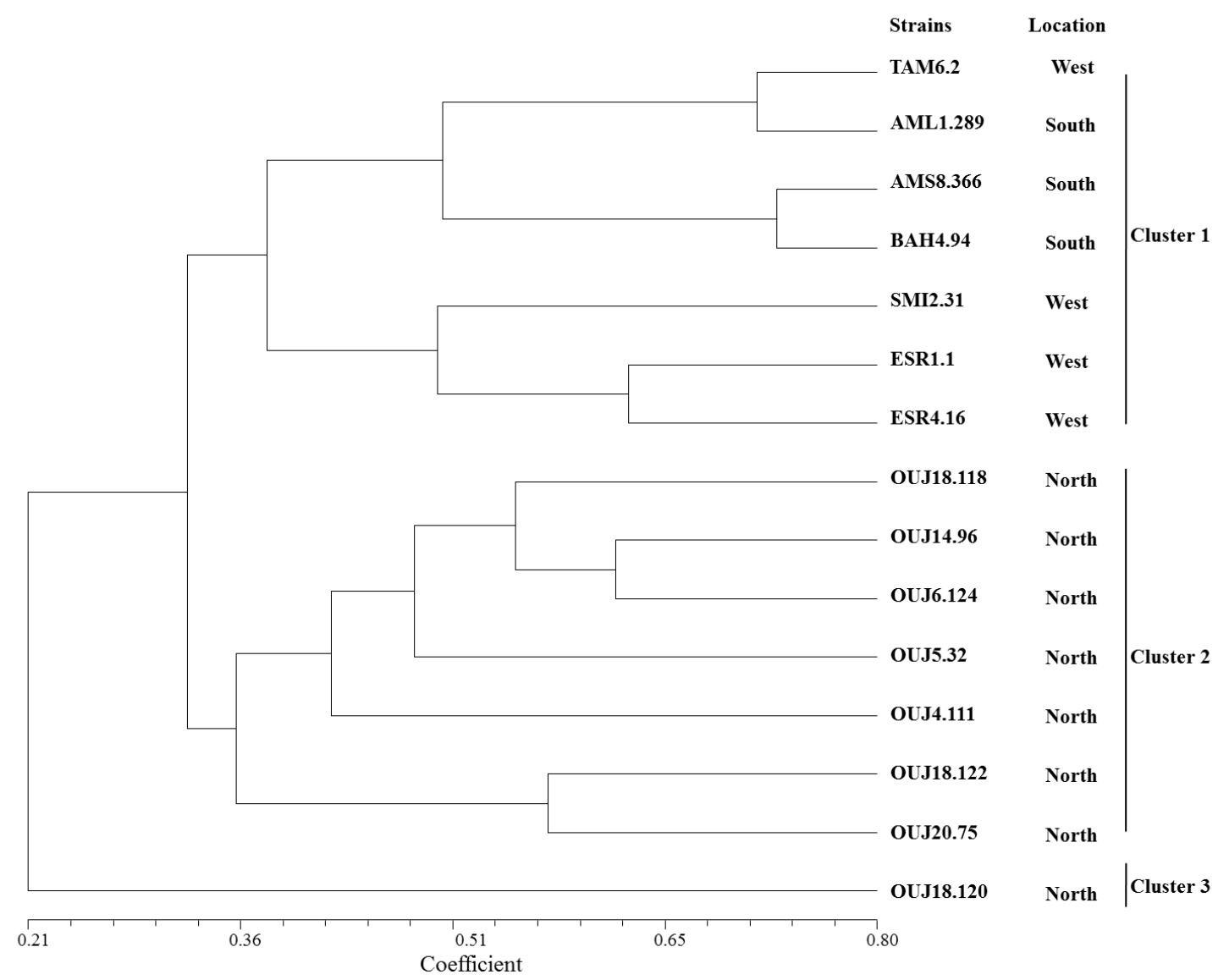

Figure 2. Dendrogram of $15 \mathrm{~B}$. bassiana strains constructed using genetic similarity analysis based on molecular profiles revealed by five RAPD markers.

\section{Molecular characterization}

The five RAPD-PCR markers have generated reproducible and multiple polymorphic DNA fragments. The RAPD patterns revealed a total of 128 well-resolved and consistent bands out of which 98 bands being polymorphic. The primers amplified between 10 (OPC5) and 34 (OPT13) RAPD bands with an average of 25.6. The size of the amplification products ranged from 180 (OPT16) to $3790 \mathrm{bp}$ (OPT14). Cluster analysis of RAPD data showed that all strains were characterized by different genotypes, indicating high genetic diversity among the strains (Figure 2). As shown in UPGMA phylogenetic tree (Figure. 2), RAPD patterns yielded three major clusters. The two major clusters each consisted of seven strains and the third group has only one strain totally diverse as compared to remaining $B$. bassiana strains. Strains from west and south of Morocco were grouped in the first cluster which further distinguished into two sub-clades, respect almost to their origin of isolation. $B$. bassiana isolated from the northern location were grouped together in the second cluster. The genetic similarity among the strains was in the range of 0.13 and 0.73 . B. bassiana strains $\mathrm{BAH} 4.94$ and AMS8.366 shared the highest genetic similarity and the lowest variability was recorded between $B$. bassiana strains OUJ14.96 and OUJ18.120.

\section{Pathogenicity against Medfly adults}

In viability tests, germination of conidia ranged from 85 to $96 \%$ after $20 \mathrm{~h}$. Mortality in controls was $5.84 \%$ at the end of bioassays and no mycoses with $B$. bassiana were recorded. Medfly was highly susceptible to all the fungal strains after being treated with conidial suspensions. There was a significant effect of $B$. bassiana on adult mortality compared with untreated $C$. capitata adults, with mean values between 71.67 and $91.67 \%$ (Table 2). There was no significant difference in the pathogenicity among strains $(F=1.004, \mathrm{df}=14, P>0.5)$. The most virulent strains to $C$. capitata adults were OUJ18.118 and 
Table 2. Susceptibility of $C$. capitata adults to fifteen locally isolated $B$. bassiana under laboratory conditions.

\begin{tabular}{|c|c|c|c|c|c|}
\hline \multicolumn{6}{|c|}{ Pathogenicity to $C$. capitata adults } \\
\hline \multirow{2}{*}{ Strain } & \multirow{2}{*}{$\begin{array}{c}\text { Mortality } \\
\text { (means } \pm \text { SE) })^{*}, \%\end{array}$} & \multicolumn{2}{|c|}{ Regression analysis of time mortality } & \multicolumn{2}{|c|}{ Kaplan-Meier survival analysis } \\
\hline & & $\mathrm{LT}_{50, \mathrm{~d}}$ & 95\% C.I & AST(means \pm SE) ${ }^{* *}, \mathrm{~d}$ & 95\% C.I \\
\hline ESR1.1 & $85.00 \pm 5.00^{a b}$ & 6.97 & $6.42-7.48$ & $7.40 \pm 0.50^{\mathrm{abc}}$ & $6.42-8.38$ \\
\hline ESR4.16 & $86.67 \pm 6.01^{\mathrm{ab}}$ & 5.44 & $4.92-5.92$ & $6.32 \pm 0.40^{\mathrm{a}}$ & $5.54-7.10$ \\
\hline SMI2.31 & $80.00 \pm 5.00^{\mathrm{ab}}$ & 7.22 & 6.74-7.72 & $7.73 \pm 0.41^{\mathrm{bc}}$ & $6.93-8.54$ \\
\hline OUJ4.111 & $85.00 \pm 2.89^{\mathrm{ab}}$ & 8.84 & $8.33-9.40$ & $9.73 \pm 0.49^{e}$ & $8.76-10.70$ \\
\hline OUJ6.124 & $78.33 \pm 6.67^{\mathrm{ab}}$ & 8.40 & $7.42-9.81$ & $8.48 \pm 0.19^{c}$ & $8.11-8.86$ \\
\hline AML1.289 & $76.67 \pm 1.67^{\mathrm{ab}}$ & 9.63 & $8.75-10.63$ & $8.21 \pm 0.33^{\mathrm{bc}}$ & $7.57-8.86$ \\
\hline AMS8.366 & $86.67 \pm 4.41^{\mathrm{ab}}$ & 9.06 & $8.46-9.67$ & $9.39 \pm 0.41^{\mathrm{e}}$ & $8.58-10.19$ \\
\hline OUJ14.96 & $85.00 \pm 2.89^{\mathrm{ab}}$ & 8.04 & $7.61-8.48$ & $8.98 \pm 0.38^{\mathrm{abc}}$ & $6.86-8.36$ \\
\hline OUJ18.118 & $91.67 \pm 3.33^{a}$ & 6.92 & $6.49-7.35$ & $7.61 \pm 0.47^{c}$ & 8.06-9.89 \\
\hline OUJ18.120 & $85.00 \pm 2.89^{a b}$ & 6.6 & $5.83-7.31$ & $6.90 \pm 0.47^{\mathrm{abc}}$ & $5.97-7.83$ \\
\hline OUJ18.122 & $90.00 \pm 5.78^{a}$ & 5.64 & $5.13-6.1$ & $6.63 \pm 0.44^{\mathrm{ab}}$ & $5.77-7.49$ \\
\hline TAM6.2 & $81.67 \pm 7.27^{a b}$ & 7.81 & 7.47-9.17 & $7.90 \pm 0.25^{b c}$ & $7.42-8.39$ \\
\hline OUJ5.32 & $86.67 \pm 7.27^{a b}$ & 8.19 & $7.47-9.17$ & $8.09 \pm 0.32^{b c}$ & $7.46-8.72$ \\
\hline OUJ20.75 & $76.67 \pm 8.82^{\mathrm{ab}}$ & 10.23 & $9.59-10.93$ & $9.72 \pm 0.25^{\mathrm{e}}$ & $9.22-10.22$ \\
\hline BAH4.94 & $71.67 \pm 6.67^{c}$ & 10.28 & $9.89-10.71$ & $9.62 \pm 0.26^{\mathrm{e}}$ & $9.10-10.13$ \\
\hline
\end{tabular}

${ }^{*}$ Means within a column followed by the same letter are not significantly different. ${ }^{* \star}$ Data in the same column followed by the same letter are not significantly different. SE: Standard Error; C.I: Confidence interval; d: day.

OUJ18.122 causing mortality rates of 91.67 and $90 \%$, respectively (Table 2 ).

The lethal time to $50 \%$ mortality $\left(L T_{50}\right)$ values were significantly different among the fungal isolates $(F=6.9$, $\mathrm{df}=14, P<0.0001)$, varying from 5.44 to $10.28 \mathrm{~d}$ (Table 2). The most pathogenic strains had $\mathrm{LT}_{50}$ values $<6 \mathrm{~d}$, and all the strains were able to kill flies faster compared with controls (Table 2). The average survival times (AST) of flies varied from 6.32 to 9.73 days. AST of Medfly adults was reduced significantly after being treated with $B$. bassiana (log-rank (Mantel-Cox), p $<0.0001$ ) compared with untreated $C$. capitata adults (Table 2).

\section{Discussion}

In a previous study, few Moroccan Beauveria strains were identified as $B$. bassiana based on ITS sequences homology using Blast Network service (Imoulan et al., 2011). In this study, additional strains were identified at species level using phylogenetic analyses of three nuclear loci (ITS, TEF1 and Bloc). Genetic diversity among the strains was performed using five RAPD markers and their effectiveness was assessed against $C$. capitata adults under laboratory conditions. MP phylogenetic analyses inferred from ITS-rDNA and combined data of TEF1 and Bloc, showed that all Beauveria strains were conclusively assigned to $B$. bassiana. Interestingly, MP phylogenetic analysis of the combined dataset was more informative by detecting additional genotypes within strains indicating that this lineage harbors cryptic diversity which conformed to the study of Rehner and Buckley (2005).

RAPD markers are suitable for genetic variability analyses because they are randomly generated from many loci throughout the genome. Different level of genetic diversity of Beauveria sp. was reported in previous studies, involving different molecular techniques (Jie and Liangen, 2010; Poeaim et al., 2014; Garrido-Jurado et al., 2015). The five tested RAPD-PCR markers provided high discrimination among strains and characterizing all the individuals by typical RAPD profiles, suggesting alongside with phylogenetic analysis of combined dataset that $B$. bassiana is an aggregate of species rather one species (Rehner and Buckley, 2005). These distinctive RAPD profiles would be useful tool for ecological studies and for long-term monitoring of the strains dispersal, efficacy and persistence after being released into the environment (Urtz and Rice, 1997; Castrillo et al., 2003; Carneiro et al., 2008).

RAPD analyses detected different genotypes strains obtained from the same geographic sites, indicating that the genetic diversity level is not related with isolation distance of fungal strains (Fegan et al., 1993). However, previous evidence reported that isolation by distance could increases genetic diversification of $B$. bassiana (Rehner et al., 2006; Fernandes et al., 2009). According to the clustering analysis of the RAPD patterns, genetic 
diversity was correlated with the geographic origin of strains and, however, no link with virulence was observed, consistent with the studies of Kaur and Padmaja (2008) and Poeaim et al. (2014). To validate this hypothesis, additional fungal strains from different geographic origin and diverse habitats are needed for further analyses.

This study reports for the first time the susceptibility of Medfly adults to Moroccan $B$. bassiana strains. The bioassays against $C$. capitata adults were performed to achieve previous assessments carried out using puparia and larvae instars of C. capitata (Imoulan et al., 2011; Imoulan and El Meziane, 2013) in order to develop bioinsecticides to control this pest in Morocco. The tested strains were obtained from a prior large screening for promising candidates using $C$. capitata pupae (Imoulan et al., 2011). The bioassays revealed that Moroccan $B$. bassiana had narrow intraspecific variations in mycosis levels (71.67-91.67\%) which could be related to the coevolution of $B$. bassiana with its host in $A$. Spinosa forests, where $C$. capitata is the sole representative species of Tephritidae (Naamani, 2004; Alaoui et al., 2010). However, large variations in the pathogenicity among $B$. bassiana strains have been reported in several previous studies (Dimbi et al., 2003; Quesada-Moraga et al., 2006).

$\mathrm{LT}_{50}$ values (5.44-6.97 d) are in the range of those reported by Quesada-Moraga et al. (2006) (4.6-6.1 days), and Qazzaz et al. (2015) (3.9-5.6 days). However they are appreciably shorter than those indicated by Konstantopoulou and Mazomenos (2005) (10.7-21.4 days) and Castillo et al. (2000) (5.6-11.0 days). In addition, AST values provided in Quesada-Moraga et al. (2006) were in the range of 5.4 and 14.4 days. Interestingly, some Moroccan $B$. bassiana strains caused AST values lower than 7 days. According to AST and $L T_{50}$ values, tested fungal stains are not only virulent to Medfly adults but would help greatly to reduce the population size and lifespan of flies before the infestation of fruits by females as far as the egg laying starts 7 days after adult emergence.

The evaluation of locally isolated $B$. bassiana is potentially useful for selecting the efficient candidates as biocontrol agents to Medfly, particularly when the pathogens tend to be used locally for crop protection. This study and our previous published works suggest that the 15 tested strains could be used as promising biological control agents towards Medfly or as a part of its integrated pest management program. Given of the ineffectiveness of commercial bioinsecticides provided by Naturalis ${ }^{\circledR}$ (Intrachem Bio Italia, Italy) against several insect pests in Morocco (Dr. S. Franceschini, personal communication), native pathogens ecologically compatible with local environmental conditions and with less impact on non-target organism would be the most useful microbial agents as alternative to conventional systemic insecticides (Inglis et al., 2001).

In conclusion, 15 locally isolated Beauveria strains were identified as $B$. bassiana using phylogenetic analyses of three nuclear genes. The genetic variability among the strains was determined using PCR-RAPD technique and a high genetic diversity was detected. In addition, the strains had a notable potential effectiveness against Medfly adults, suggesting their usefulness as biocontrol agents against Medfly for crops protection. Different RAPD profiles will help to monitor stains dispersal and persistence after being introduced in the environment infested with $C$. capitata. Additional research is needed to determine the effectiveness of these strains under field conditions to assess certainly their real contribution as a promising biological control agent against Medfly.

\section{CONFLICT OF INTEREST}

The authors declare that they have no conflict of interest.

\section{ACKNOWLEDGMENTS}

This work was financially supported by PROTARS II grant (P51/02) from the Moroccan Ministry of Higher Education and Scientific Research. A.I wishes to acknowledge CNRST for Doctorate research fellowship (b3/018). Thanks to Prof. Yi-Jian Yao, Institute of Microbiology, Chinese Academy of Sciences, for help in molecular identification of Beauveria strains.

\section{REFERENCES}

Alaoui, A., Imoulan, A., El Alaoui-Talibi, Z., \& El Meziane, A. (2010). Genetic structure of Mediterranean fruit fly (Ceratitis capitata) populations from Moroccan endemic forest of Argania spinosa. Int. J. Agric. Biol., 12, 291-298

Arouri, R., Le Goff, G., Hemden, H., Navarro-Llopis, V., M'saad, M., Castañera, P., Feyereisen, R., Hernández-Crespo, P., \& Ortego, F. (2015). Resistance to lambda-cyhalothrin in Spanish field populations of Ceratitis capitata and metabolic resistance mediated by $\mathrm{P} 450$ in a resistant strain. Pest Mag. sci., 71, 1281-91.

Bidochka, M. J., Mcdonal, M. A., Leger, R. J. S., \& Roberts, D. W. (1994). Differentiation of species and strains of entomopathogenic fungi by random amplification of polymorphic DNA (RAPD). Curr. Genet., 25, 107-113.

Butt, T. M., \& Goettel, M. S. (2000). Bioassays of entomogenous fungi. In: Navon, A., \& Ascher, K. R. S. (ed) Bioassays of entomopathogenic microbes and nematodes. CABI, London, United Kingdom, Pp. 141-195.

Carneiro A. A., Gomes E. A., Guimaraes C. T., Fernandes F. T., Carneiro N. P., \& Cruz L. (2008). Molecular characterization and pathogenicity of isolates of Beauveria spp. to fall armyworm. Pesqui Agropecu Bras., 43, 513-520.

Castillo, M. A., Moya, P., Hernandez, E., \& Fera, E. P. Y. 
(2000). Susceptibility of Ceratitis capitata Wiedemann (Diptera: Tephritidae) to entomopathogenic fungi and their extracts. Biol. Control, 19, 274-282.

Castrillo, L. A., Vandenberg, J. D., \& Wraight, S. P. (2003). Strain specific detection of introduced Beauveria bassiana in agricultural field by use of sequence-characterized amplified region markers. J. Invertebr. Pathol., 82, 75-83.

D'Aquino, S., Cocco, A., Ortu, S., \& Schirra, M. (2011). Effects of kaolin-based particle film to control Ceratitis capitata (Diptera: Tephritidae) infestations and postharvest decay in citrus and stone fruit. Crop Protection, 30, 1079-1086.

Dimbi, S., Maniania, N. K., Lux, S. A., Ekesi, S., \& Mueke, J. K. (2003). Pathogenicity of Metarhizium anisopliae (Metsch.) Sorokin and Beauveria bassiana (Balsamo) Vuillemin, to three adult fruit fly species: Ceratitis capitata (Weidemann), C. rosa var. fasciventris Karsch and $C$. cosyra (Walker) (Diptera: Tephritidae). Mycopathologia, 156, 375-382.

Ekesi, S., Dimbi, S., \& Maniania, N. K. (2007). The role of entomopathogenic fungi in the integrated management of tephritid fruit flies (Diptera: Tephritidae) with emphasis on species occurring in Africa. In: Ekesi, S., \& Maniania, N. $\mathrm{K}$. (ed) Use of entomopathogenic fungi in biological pest management. Research SignPost, Pp. 239-274

Fegan, M., Manners, J. M., MacLean, D. J., Irwin, J. A. G., Samuels, K. D. Z., Holdom, D. G., \& Li, D. P. (1993). Random amplified polymorphic DNA markers reveal a high degree of genetic diversity in the entomopathogenic fungus Metarhizium anisopliae var. anisopliae. J. Gen. Microbiol., 139, 2075-2081

Felsenstein, J. (1985). Confidence limits on phylogenies: An approach using the bootstrap. Evolution, 39, 783-791.

Fernandes, É., Moraes, Á., Pacheco, R., Rangel, D., Miller, M., Bittencourt, V., \& Roberts, D. (2009). Genetic diversity among Brazilian isolates of Beauveria bassiana: comparisons with non-Brazilian isolates and other Beauveria species. J. Appl. Microbiol., 107, 760-774.

Garrido-Jurado, I., Fernández-Bravo, M., Campos, C., \& Quesada-Moraga E. (2015). Diversity of entomopathogenic Hypocreales in soil and phylloplanes of five Mediterranean cropping systems. J. Invertebr. Pathol., 130, 97-106.

Goettel, M. S., Eilenberg, J., \& Glare, T. (2005). Entomopathogenic fungi and their role in regulation of insect populations. Compr. Mol. Insect Sci., 6, 361-406.

Hall, T. A. (1999). BioEdit: a user-friendly biological sequence alignment editor and analysis program for Windows 95/98/NT. Nucl. Acid Symp., 41, 95-98.

Imoulan, A., \& Elmeziane, A. (2013). Pathogenicity of Beauveria bassiana isolated from Moroccan Argan forests soil against larvae of Ceratitis capitata (Diptera: Tephritidae) in laboratory conditions. World J. Microbiol. Biotechnol. 30, 959-965.

Imoulan, A., Alaoui, A., \& El Meziane, A. (2011). Natural occurrence of soil-borne entomopathogenic fungi in the Moroccan Endemic forest of Argania spinosa and their pathogenicity to Ceratitis capitata. World J. Microbiol. Biotechnol., 27, 2619-2628

Inglis, G. D., Goettel, M. S., Butt, M. T., \& Strasser, H. (2001). Use of hyphomyceteous fungi for managing insect Pests. In: Butt, T. M, Jackson, C., \& Magan, N. (ed) Fungi as Biocontrol Agents: Progress, Problems and Potential. CABI Press, Wallingford, UK, Pp. 23-69.
Jie, J., \& Liangen, S. (2010). RAPD analyse to detect genetic diversity of Beauveria bassiana from the silkworm, Bombyx mori in China.

Kaur, G., \& Padmaja, V. (2008). Evaluation of Beauveria bassiana isolates for virulence against Spodoptera litura (Fab.) (Lepidoptera: Noctuidae) and their characterization by RAPD-PCR. Afr J Microbiol Res 2:299-307.

Konstantopoulou, M. A., \& Mazomenos, B. E. (2005). Evaluation of Beauveria bassiana and $B$. brongniartii strains and four wild-type fungal species against adults of Bactrocera oleae and Ceratitis capitata. Bio. Control. 50, 293-305.

Naamani, K. (2004). Etude de l'Entomofaune de l'Arganier (Argania spinosa (L). Skeels) et de la bio-écologie de son ravageur Ceratitis capitata Wiedemann (Diptere: Tephritidae) dans la région d'Essaouira (Maroc). Dissertation, University of Cadi-Ayyad, Morocco.

Poeaim, S., Hangtrakul, S., \& Soytong, K. (2014). Genetic diversity of Beauveria sp. isolated in Thailand. J. Agric. Technol., 10, 607-616.

Qazzaz, F. O., Al-masri, M. I., \& Barakat, R. M. (2015) Effectiveness of Beauveria bassiana native isolates in the biological control of the Mediterranean fruit fly (Ceratitis capitata). Adv. Entomol., 3, 44-55.

Quesada-Moraga, E., Ruíz-García, A., \& Santiago-Álvarez, C. (2006). Laboratory evaluation of entomopathogenic fungi Beauveria bassiana and Metarhizium anisopliae against puparia and adults of Ceratitis capitata (Diptera: Tephritidae). Econ. Entomol., 99, 1955-1966.

Rehner, S. A., Minnis, A. M., Sung, G-H., Luangsa-ard, J. J., Devotto, L., \& Humber, R. A. (2011). Phylogeny and systematics of the anamorphic, entomopathogenic genus Beauveria. Mycologia, 103, 1055-73.

Rehner, S. A., Posada, F., Buckley, E. P., Infante, F., Castillo, A., \& Vega, F. E. (2006). Phylogenetic origins of African and Neotropical Beauveria bassiana s.I. pathogens of the coffee berry borer, Hypothenemus hampei. J. Invertebr. Pathol., 93, 11-21.

Rehner, S.A., \& Buckley, E. (2005). A Beauveria phylogeny inferred from nuclear ITS and EF1-alpha sequences: evidence for cryptic diversification and links to Cordyceps teleomorphs. Mycologia, 97, 84-98.

Rohlf, F. J. (2000). NTSYS-PC Numerical Taxonomy and Multivariate Analysis System, v. 2.1, Manual. Applied Biostatistics Inc, N.Y.

Sneath, P. H. A., \& Sokal, R. R. (1973). Numerical Taxonomy. Freeman, San Francisco.

Swofford, D. L., (2003). PAUP*. Phylogenetic analysis using parsimony ( ${ }^{*}$ and other methods), version $4 \mathrm{~b} 10$. Sinauer Associates, Sunderland.

Thompson, J. D., Gibson, T. J., Plewniak, F., Jeanmougin, F., \& Higgins, D. G. (1997). The Clustal X windows interface: flexible strategies for multiple sequence alignment by quality analysis tools. Nucleic Acids Res., 24, 4876-4882.

Throne, J. E., Weaver, D. K., Chew, V., \& Baker, J. E. (1995). Probit analysis of correlated data: multiple observations over time at one concentration. J. Econ. Entomol. 88, 1510-1512.

Urtz, B. E, \& Rice, W. C. (1997). RAPD-PCR characterisation of Beauveria bassiana isolates from the rice water weevil Lissorhoptrus opyzophilus. Lett. Appl. Microbiol., 25, 405409.

Vaidya, G., Lohman, D. J., Meier, R. (2011). SequenceMatrix: 
concatenation software for the fast assembly of multi-gene datasets with character set and codon information. Cladistics, 27, 171-180.

White, I. M., \& Elson-Harris, M. (1994). Fruit flies of economic significance: their identification and bionomics. CAB International, Wallingford, Oxon, UK.

White, T. J., Bruns, T., Lee, S., \& Taylor, J. W. (1990). Amplification and direct sequencing of fungal ribosomal RNA genes for phylogenetics. In: Innis M. A., Gelfand D. H., Sninsky J. J., White T. J. (ed) PCR protocols: a guide to methods and applications. Academic Press, New York, Pp. 315-322.
Yao, Y-J., Pegler, D. N., \& Chase, M. W. (1999). Application of ITS (nrDNA) sequences in the phylogenetic study of Tyromyces s.I. Mycological Research, 103, 219-229. 